Scientił studia, São Paulo, v. 12, n. 3, p. 601-5, 2014

\title{
Desbravando a tecnologia
}

\author{
Cristiano Cordeiro Gruz
}

\section{Filosofia da tecnologia: um convite}

Alberto Cupani

Editora da Universidade Federal de Santa Catarina (UFSC)

Florianópolis, 2011, 234 págs.

David Wallace, romancista norte-americano, inicia um de seus textos com uma passagem provocativa: "dois peixinhos estão nadando juntos e cruzam com um peixe mais velho, nadando em sentido contrário. Ele os cumprimenta e diz:

- Bom dia, meninos. Como está a água?

Os dois peixinhos nadam mais um pouco, até que um deles olha para o outro e pergunta:

-Água? Que diabo é isso?" (Wallace, 2008, p. 105).

Nesse texto, que é um discurso de paraninfo para uma turma de graduandos, Wallace discorre sobre questões existenciais profundas, tão urgentes e presentes ao ser humano, na sua busca por construção de sentido, quanto usualmente por nós negligenciadas.

Não é exatamente desse tipo de questões que Cupani se ocupará em sua obra Filosofia da tecnologia: um convite. Contudo, assim como a água da história de Wallace, a tecnologia, de tão presente em nossas vidas, costuma apresentar-se como se transparente. Com efeito, desde as máquinas que facilitam o nosso dia-a-dia, até as técnicas que tornam a cura de doenças mais eficaz, a tecnologia está por toda parte. Que diabos, no entanto, é de fato a tecnologia? Ela é passível de ser socialmente controlada ou se desenvolve de maneira automática e autônoma? Ela é neutra, estando imune a valores sociais, ou, ao contrário, incorpora-os, alterando-se em função dos valores específicos que a moldam? Se ela incorpora valores, quais questões éticas são ou poderiam ser pertinentemente levantadas com relação ao processo de seu desenvolvimento? Ela impacta a vida humana individual e coletiva? Que nível de controle político, democrático, é lícito requerer em contrapartida? Que tipo de conhecimento fundamenta a atividade técnica? 
Dessa forma, no sentido de oferecer ao leitor uma primeira aproximação filosófica ao tema, com algumas alternativas de respostas às questões anteriores, Cupani propõe-nos uma jornada que parte da percepção da complexidade disso que se chama tecnologia, até chegar à análise do que se convencionou chamar "determinismo" ou “autonomia” tecnológica. É assim que, no primeiro capítulo, a tecnologia será descortinada em sua multiplicidade e ambivalência, como um modo de fazer coisas, associado a um saber, diante do qual não apenas cabem, mas urgem serem feitas indagações de ordem ontológica, epistemológica, axiológica e ético-política. Tais questões não são abordadas separadamente nos capítulos que se seguem, à exceção talvez dos três últimos, mas apresentadas de modo transversal ao longo da maior parte do texto, valendo-se, para isso, também de contribuições vindas da história e da sociologia.

Ao iniciar sua análise sobre o fenômeno tecnológico, Cupani apresenta, no segundo capítulo, os estudos clássicos da área, de autores que escreveram antes da criação do ramo de filosofia da tecnologia, que se consolida apenas nos anos 1970. Os três primeiros - Ortega y Gasset, Heidegger e Gehlen - abordaram o fenômeno tecnológico a partir de suas compreensões de mundo mais amplas, buscando apontar, a partir delas, tanto a causa da gênese da tecnologia e sua transformação ao longo do tempo (mormente a transformação trazida com a modernidade), quanto seus impactos benéficos e maléficos sobre o ser humano. O quarto é o francês Gilbert Simondon, que, além de filósofo, também era engenheiro. Sua análise é considerada pioneira na área, esmiuçando a tecnologia a partir de dentro, ou seja, a partir do olhar do engenheiro. Sua compreensão é que desconhecemos a tecnologia, razão que nos leva a julgá-la de maneira inadequada, demonstrando, com isso, mais a tacanhez de nossa cultura do que propriamente consequências de fato negativas do desenvolvimento tecnológico. A tecnicidade, ou seja, a essência da tecnologia, deve ser concebida, segundo o autor, como um modo de relação do homem com o mundo (ao lado do estético, do religioso etc.), que caracteriza a maneira com que fomos aprendendo a lidar com a natureza. Assim, para Simondon, faltar-nos-ia uma educação tecnológica desde a infância que nos ajudasse a nos colocarmos no mundo no mesmo nível que as máquinas, elevando-nos em nossa cultura, segundo as possibilidades oferecidas por elas.

No terceiro capítulo, Cupani apresentará a visão do historiador Lewis Mumford sobre a tecnologia. Este, ao analisar transformações significativas por que passa a Europa no final da Idade Média, compreende a máquina moderna como a conjugação de duas importantes disposições humanas da época: a vontade de dominar o ambiente, aliada à vontade de poder. Dessa associação adviria a ruptura com o passado cultural, a crescente exploração do trabalhador e a poluição ambiental, a que se somarão, posteriormente, a forte colaboração da ciência e o surgimento da figura característica da sociedade industrial, o técnico especializado. Nosso desafio atual seria, então, o de 
superarmos o mito da máquina, assumindo-nos não como homo faber, mas como homo sapiens, seres que, em sendo capazes de pensar, são capazes de conceber e utilizar ferramentas, além de serem capazes de diversas outras coisas. Desse modo, ao imperativo clássico da técnica - o de que há uma única velocidade eficiente: mais rápido; um único destino atraente: mais longe; uma única medida desejável: maior; uma única meta quantitativa racional: mais - precisamos responder com o desenvolvimento das outras incalculáveis potencialidades de autoatualização e autotranscendência que temos em nós.

Daí em diante, Cupani apresentará as análises e reflexões de diversos filósofos da tecnologia. É assim que o quarto capítulo traz a análise conceitual de Mario Bunge; o quinto mostra a interpretação do significado da experiência humana condicionada pela tecnologia segundo Don Ihde, Hubert Dreyfus e Albert Borgmann (estudos de inspiração fenomenológica e hermenêutica); e o sexto expõe a relação entre tecnologia e o exercício do poder de acordo com Langdon Winner e Andrew Feenberg. Em síntese, Bunge propõe uma tecnologia axiologicamente não neutra, calcada em conhecimento técnico e científico irredutíveis um ao outro, e desenvolvida por tecnólogos eticamente imputáveis pelas consequências do uso dos artefatos por eles projetados. Os fenomenólogos, em seu esforço por descrever pormenorizadamente todos os matizes do fenômeno tecnológico, sublinham aspectos importantes usualmente não percebidos de nosso ser-tecnologicamente-no-mundo, alertando-nos, dentre outras coisas, com respeito à tendência desumanizadora de nos "tecnologizarmos". Por fim, Winner e Feenberg, ainda que por caminhos e análises distintas, sustentam que a tecnologia também é vetor de valores sociais, de sorte que o controle político e democrático sobre o seu desenvolvimento é não apenas possível, dentro de certos limites, como altamente desejável.

Nos três últimos capítulos, ao expor o entendimento de distintos autores, Cupani aprofunda alguns aspectos epistemológicos (capítulo 7), sociais, políticos e existenciais (capítulo 8), e ontológicos (capítulo 9) da tecnologia, em boa medida já tocados nos capítulos anteriores. Insiste então na existência de um conhecimento técnico irredutível ao científico, ainda que possa existir significativo grau de interdependência entre eles, sendo ambos necessários para o desenvolvimento tecnológico. Além disso, malgrado diversos indícios do forte impacto da tecnologia em nossa vida, que afeta nossa forma de experimentar e significar a existência individual e coletiva, o juízo positivo ou negativo disso está em boa medida relacionado às ideologias às quais se vincula aquele que o emite. $O$ cuidado na análise crítica da tecnologia deve ser, então, o de buscarmos sempre despirmo-nos de nossas preconcepções, de modo a, por exemplo, não tomarmos como certo, geral ou universal - e, por isso, potencialmente terrível -, aquilo que é de origem múltipla, local ou circunstancial. Por fim, no que tange ao argumento da impossibilidade de se controlar o desenvolvimento técnico, a partir do mo- 
mento em que ele é posto em movimento, tal coisa parece dar-se menos por um poder irresistível e inato da tecnologia, do que por uma progressiva adesão muitas vezes inconsciente de nossos semelhantes ao "projeto tecnológico". Assim, ainda que pareçam existir aspectos essencialmente inalteráveis na tecnologia, não está dado nela que sejamos obrigados a prestar-lhe culto e/ou a nos adequarmos a todos os seus propósitos (supostamente) despóticos.

Na leitura de Filosofia da tecnologia: um convite, é importante que tenhamos em mente uma advertência expressa de Cupani com relação ao que ele pretendeu com a obra: ser uma iniciação para quem não conhece o tema e não domina outras línguas (de modo que não teria condições de recorrer a outros bons livros introdutórios e à boa parte dos autores por ele aqui tratados, que não contam ainda com traduções para o português). Nesse sentido, o autor realiza bastante bem sua tarefa, apresentando diversos dos aspectos essenciais relacionados à reflexão filosófica sobre a tecnologia de modo usualmente claro, sucinto e provocativo. Trata-se, entretanto, de um livro de filosofia. Dessa forma, o leitor deverá estar ciente de que, para compreendê-lo, não poderá proceder a uma leitura meramente mecânica: ele precisará estar disposto a refletir.

A característica marcante da obra é que ela oferece um amplo panorama sobre o tema, uma coletânea de pontos de vista nem sempre contraditórios, mas muitas vezes potencialmente complementares. A ideia, também explicitamente expressa, do autor não é fechar uma definição e uma compreensão canônicas acerca da tecnologia, até porque tal coisa continua em ampla disputa. Sua intenção é suscitar em nós a inquietação que nos fará buscar aprofundarmos nossa compreensão e nossa análise sobre o assunto. Cupani logra, em diversas partes de seu livro, um feito notável: possibilitar ao leitor não apenas enxergar e ser capaz de analisar de forma crítica a "água" tecnológica em que habita, mas, tão importante quanto isso, questionar suas próprias preconcepções. Com efeito, ainda que apresente o tema majoritariamente a partir da ótica de pensadores críticos, sua abordagem se dá segundo uma perspectiva "desarmada", que possibilita ou fundamenta um diálogo, muito mais do que mune fundamentalistas de dogmas, verdades ou intransigências. Em um tempo no qual nossa dificuldade de dialogar com o diferente, de escutá-lo, torna-se mais evidente ou mais potencializada pelas redes sociais, tal obra cumpre um papel bastante interessante, mostrando-nos não apenas a característica multifacetada do fenômeno técnico, como as possibilidades de enriquecimento de nossa compreensão dele a partir de uma abordagem plural, que conjuga argumentos tradicionalmente atribuídos às esquerdas e às direitas ideológicas, em um todo menos panfletário do que aquilo que usualmente encontramos. Exatamente por isso, mais afeito à honestidade intelectual.

Seu texto, então, ajuda-nos a compreender melhor o fenômeno tecnológico, abandonando as certezas próprias daqueles que desconhecem; a percebermos possi- 
bilidades de afetá-lo, de incidirmos sobre ele, sem demonizá-lo; e a buscarmos aprofundarmo-nos na compreensão da tecnologia, superando preconceitos, naturalizações e fatalismos. Dessa forma, o livro fornece mais consciência acerca da realidade técnica em que estamos inseridos. Ao fazer isso, se não nos lança diretamente nos mesmos tipos de questões existenciais apresentadas por Wallace, nem por isso ajudanos menos na tarefa de construirmos, individual e coletivamente, uma vida que valha realmente a pena ser vivida, sem aprisionamentos ou apequenamentos contingentes, vendidos ou assumidos como inevitáveis ou insuperáveis. Talvez, como afirma Feenberg (2002), a tecnologia não seja destino, mas construção, opção. E se é de fato assim, fazse mister, antes de tudo, aprofundar-se no assunto. $\rightarrow$

Agradecimentos. Esta resenha faz parte de minha pesquisa de doutorado, financiada pela Fundação de Amparo à Pesquisa do Estado de São Paulo (FAPESP). Processo 2013/18757-0.

Cristiano Cordeiro Gruz Programa de Pós-Graduação em Filosofia,

Departamento de Filosofia, Faculdade de Filosofia, Letras e Ciências Humanas, Universidade de São Paulo, Brasil. cristianoccruz@yahoo.com.br Exploring technology

\section{REFERÊNGIAS BIBLIOGRÁFICAS}

Cupani, A. Filosofia da tecnologia: um convite. Florianópolis: Editora da Universidade Federal de Santa Catarina, 2011.

Feenberg, A. Transforming technology: a critical theory revisited. New York: Oxford University Press, 2002. Wallace, D. F. A liberdade de ver os outros. Revista Piauí, 25, p. 105, 2008. Disponível em: <http:// revistapiaui.estadao.com.br/edicao-25/despedida/a-liberdade-de-ver-os-outros>. Acesso em: ०4 fev. 2014. 